\title{
Adverse effects of inhaled sand dust particles on the respiratory organs of sheep and goats exposed to severe sand storms in Mongolia
}

\author{
Yoshimi Kobayashi ${ }^{1}$, Akinori Shimada ${ }^{2}$, Mai Nemoto ${ }^{1}$, Takehito Morita ${ }^{1}$, \\ Altanchimeg Adilbish ${ }^{3}$, Mungun-Ochir Bayasgalan ${ }^{3}$ \\ ${ }^{1}$ Department of Veterinary Pathology, Tottori University, Tottori-shi, Tottori, Japan \\ ${ }^{2}$ Department of Pathology, School of Life and Environmental Science, Azabu University, \\ Sagamihara-shi, 252-5201 Kanagawa, Japan \\ ${ }^{3}$ Institute of Veterinary Medicine, Zaisan, Ulaanbaatar, Mongolia
}

\begin{abstract}
Sand storms in Mongolia have increased in frequency and scale, resulting in increased exposure of the inhabitants of Asian countries, including Japan and Korea, to Asian sand dust (ASD), which results in adverse effects on the respiratory system. However, there is no information on the health risks of severe sand storms in domestic animals in Mongolia. The aim of the study was to investigate the effects of sand dust particles on the respiratory organs, including the lungs and tracheobronchial lymph nodes, of sheep and goats exposed to severe sand storms in Mongolia. Seven adult sheep and 4 adult goats that had been exposed to sand storms and 3 sheep with no history of exposure were included in this study. Lung tissues and tracheobronchial lymph nodes were subjected to histopathological and immunohistochemical examination. The mineralogical contents of the lungs and lymph nodes were determined using inductively coupled plasma atomic emission spectroscopy. Fibrosis and granulomatous lesions comprising macrophages containing fine sand dust particles were observed exclusively in the lungs of sheep and goats exposed to sand storms. The activity of macrophages was also demonstrated by the presence of IL-6, TNF, and lysozyme. In addition, silicon, which is the major element of ASD (kosa aerosol), was detected exclusively in the lung tissues of the exposed animals. Our findings suggest that exposure to sand dust particles may affect the respiratory systems of domestic animals during their relatively short life span. (Folia Histochemica et Cytobiologica 2014, Vol. 52, No. 3, 244-249)
\end{abstract}

Key words: domestic animal; sand dust; silicon; lungs; fibrosis; pulmonary toxicity; activated macrophages; sheep; goat

\section{Introduction}

Asian sand dust (ASD), also known as kosa aerosol, originates from the arid deserts of Mongolia and China annually and causes severe air pollution in the Asia-Pacific area, including China, Korea, and Japan [1]. Epidemiological studies of ASD in humans

Correspondence address: A. Shimada, Professor of Pathology, Department of Pathology, School of Life and Environmental Science, Azabu University,

Sagamihara-shi, 252-5201 Kanagawa, Japan

e-mail: a-shimada@azabu-u.ac.jp have shown that ambient ASD particles are associated with increased pulmonary and cardiovascular problems and mortality in Korea [2-4] and Taiwan [5]. The frequency and scale of dust events producing ASD aerosols have increased rapidly in the East Asian region since 2000 [6]. Because of recent environmental changes, humans are at an increased risk of ASD exposure and adverse respiratory system conditions [7].

Occupational exposure to crystalline silica is associated with silicosis, lung cancer, pulmonary tuberculosis, and chronic obstructive pulmonary disease [8]. In addition, silicosis patients often develop autoimmune diseases $[9,10]$. Experimental chronic 
exposure to crystalline silica $\left(\mathrm{SiO}_{2}\right)$ reportedly causes granuloma formation [11-15] and/or fibrosis [16] in rats. In addition, granulomatous inflammation, characterized by the accumulation of epithelioid macrophages containing crystalline silica particles, in the tracheobronchial lymph nodes, has been reported in rats exposed to crystalline silica $[12,17,18]$. Silica is the major mineralogical component of ASD [19]. Previous studies examining experimental pulmonary toxicity of ASD particles showed that the mineralogical components of ASD particles that were free from chemical and biological pollutants cause acute $[20,21]$ and chronic [22] inflammatory changes with granuloma formation in the lung tissues of mice. Similar mineral deposits of unknown origin in the tracheobronchial lymph nodes were reported in dogs [23, 24].

The frequency of sand storms has increased with recent significant climate changes in Mongolia [25], resulting in growing concern for the health of exposed inhabitants and animals. This study aimed to investigate the effects of sand dust particles on the respiratory organs, including the lungs and tracheobronchial lymph nodes, of sheep and goats exposed to severe sand storms in Mongolia.

\section{Material and methods}

Animals. Lungs and tracheobronchial lymph nodes were obtained from 7 sheep (Ovis aries) and 4 goats (Capra aegagrus hircus) which were over 2 years of age. The animals were local to the Sukhbaatar and Umnugovi provinces of Mongolia (Table 1), regions that have experienced severe sand storms in the past 5 years. Moreover, three 2-year-old sheep with no history of exposure to sand storms were obtained from Japan and used as control animals.

Histopathology. Lung tissues and tracheobronchial lymph nodes from 7 sheep and 4 goats from Mongolia and 3 sheep from Japan were subjected to pathological examination. Tissues from the lungs and lymph nodes were fixed in $10 \%$ neutral phosphate-buffered formalin, processed routinely, and embedded in paraffin wax for histopathological and immunohistochemical examination. Approximately $3-\mu \mathrm{m}$-thick sections were cut and stained with hematoxylin and eosin (HE) and Masson's trichrome stain.

Immunohistochemistry. Selected paraffin-embedded sections from the lungs were used for the immunohistochemical detection of $\alpha$-smooth muscle actin ( $\alpha$-SMA), lysozyme, interleukin-6 (IL-6), and tumor necrosis factor alpha $(\mathrm{TNF}-\alpha)$. For antigen retrieval, sections were placed in a citrate buffer solution ( $\mathrm{pH}$ 5.4) and microwaved ( $\alpha$-SMA, IL-6, TNF- $\alpha$ ) or treated with protein kinase (lysozyme). Endogenous peroxidase activity was quenched by adding
$3 \% \mathrm{H}_{2} \mathrm{O}_{2}$ at room temperature for $30 \mathrm{~min}$. The slides were then blocked with $10 \%$ normal goat serum for $5 \mathrm{~min}$ by microwave treatment. The sections were incubated with primary antibodies overnight at $4^{\circ} \mathrm{C}$ (anti- $\alpha$-SMA, Dako, Glostrup, Denmark, 1:80 dilution; anti-lysozyme, Dako, 1:500 dilution; anti-IL-6, Abcam, Tokyo, Japan; and anti-TNF- $\alpha$, Monosan, Uden, Netherlands, 1:15 dilution). Primary antibodies were replaced with phosphate-buffered saline in negative controls. After the primary antibody reaction, the sections were incubated with a peroxidase-labeled polymer conjugated to secondary anti-mouse and anti-rabbit antibodies [En Vision + kit/HRP (DAB), Dako] for $30 \mathrm{~min}$ at room temperature. Positive reactions were indicated by brown staining when 3,3'-diaminobenzidine tetrahydrochloride (DAB) was used as the chromogen. The sections were then counterstained with hematoxylin.

Elemental analysis. The mineralogical contents of the lungs and lymph nodes were determined using inductively coupled plasma atomic emission spectroscopy (ICPS-8100, Shimazu, Kyoto, Japan). Silicon and aluminum, which are the major mineralogical components of ASD (kosa) [21, 26], were analyzed. Lung tissues and tracheobronchial lymph nodes from the unexposed (No. 1, No. 2) and exposed animals (No. 4, No. 6) were used.

\section{Results}

The animals exhibited no clinical symptoms related to respiratory failure before necropsy. There were no gross findings except for occasional terminal hemorrhagic foci in the lungs. On histopathological examination, changes were identified in the lung and lymph nodes (Table 1). In contrast to the thin alveoli with scant fibrous bundles in control sheep (Figure 1A, B), mild to moderate emphysema and diffuse fibrous thickening of the alveolar walls with occasional alveolar macrophages containing sand dust particles were observed in the lungs from all exposed animals (Figure 1C, Table 1). Masson trichrome-positive fibrous bundles (Figure 1D) and $\alpha$-SMA-positive myofibroblasts and fibrillar structures (Figure 1D, inset) were observed in thickened alveolar walls. Granulomatous lesions comprising macrophages containing fine sand dust particles were occasionally detected in the bronchiolar lymphoid tissues of the lungs from the eight exposed animals and were frequently detected in the tracheobronchial lymph nodes of all exposed animals. The sand dust particles appeared birefringent and white in color under polarized light (Figure 2A-C). Macrophages in the alveolar and granulomatous lesions showed intense immunoreactivity for lysozyme (Figure 2D, 3A), IL-6 (Figure 3B), and TNF- $\alpha$ (Figure 3C). 
Table 1. Clinical history and pathological findings

\begin{tabular}{|c|c|c|c|c|c|c|c|c|c|}
\hline \multirow[t]{2}{*}{ No. } & \multirow{2}{*}{$\begin{array}{c}\text { Age } \\
\text { (year) }\end{array}$} & \multirow[t]{2}{*}{ Animal } & \multirow[t]{2}{*}{ Place } & \multirow{2}{*}{$\begin{array}{l}\text { Sand } \\
\text { storm }\end{array}$} & \multicolumn{2}{|c|}{ Deposits of sand particles } & \multicolumn{2}{|c|}{ Granulomatous lesion } & \multirow{2}{*}{$\begin{array}{c}\text { Fibrosis } \\
\text { Alveolar wall }\end{array}$} \\
\hline & & & & & Lung & Lymph node & Lung & Lymph node & \\
\hline 1 & 2 & Sheep & Japan & - & - & - & - & - & - \\
\hline 2 & 2 & Sheep & Japan & - & - & - & - & - & - \\
\hline 3 & 2 & Sheep & Japan & - & - & - & - & - & - \\
\hline 4 & $4 \sim 6$ & Sheep & $\mathrm{S}$ & ++ & + & + & - & + & + \\
\hline 5 & $4 \sim 6$ & Sheep & $\mathrm{S}$ & ++ & + & + & - & + & + \\
\hline 6 & $4 \sim 6$ & Sheep & S & ++ & + & ++ & + & ++ & ++ \\
\hline 7 & $>8$ & Sheep & $S$ & ++ & + & + & + & + & + \\
\hline 8 & $>7$ & Goat & $S$ & ++ & + & + & + & + & ++ \\
\hline 9 & $>7$ & Goat & $S$ & ++ & + & + & + & + & + \\
\hline 10 & $>7$ & Goat & $S$ & ++ & + & + & - & + & + \\
\hline 11 & $>3$ & Sheep & $\mathrm{U}$ & +++ & + & + & + & + & + \\
\hline 12 & $>3$ & Sheep & $\mathrm{U}$ & +++ & + & ++ & + & ++ & ++ \\
\hline 13 & $>2$ & Sheep & $\mathrm{U}$ & +++ & ++ & ++ & + & ++ & ++ \\
\hline 14 & 8 & Goat & $\mathrm{U}$ & +++ & ++ & ++ & + & ++ & + \\
\hline
\end{tabular}

U - Umnugovi; S - Sukhbaatar; +mild; + +moderate; ++ +severe

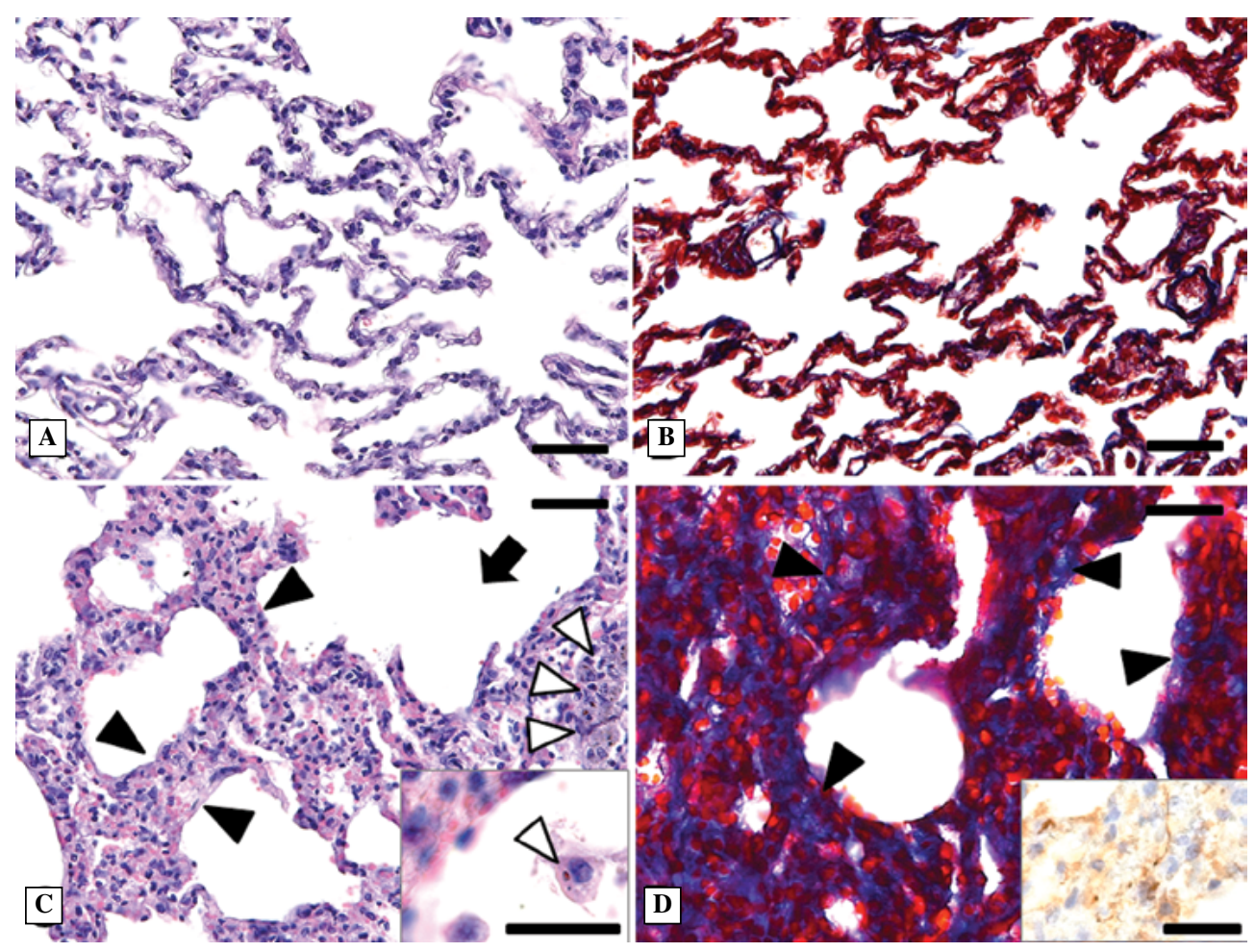

Figure 1. Histological structure of lung of control and sand storms-exposed sheep. A, B. Control sheep (No. 1). Lungs present thin alveoli with scant fibrous bundles; C, D. Sand storms-exposed sheep (No. 6). C. Lung emphysema (black arrow), and fibrous thickening (black arrowheads) of the alveolar walls and, occasionally, alveolar macrophages containing sand particles (white arrowheads). D. Masson trichrome-positive fibrous bundles (black arrowheads) and $\alpha$-SMA-positive myofibroblasts and fibrillar structures (inset) are present in the thickened alveolar septa. A, C: Hematoxylin and eosin (H \& E) staining. B, D: Masson trichrome staining, D inset: $\alpha$-SMA immunohistochemistry. Scale bars $=50 \mu \mathrm{m}$ 


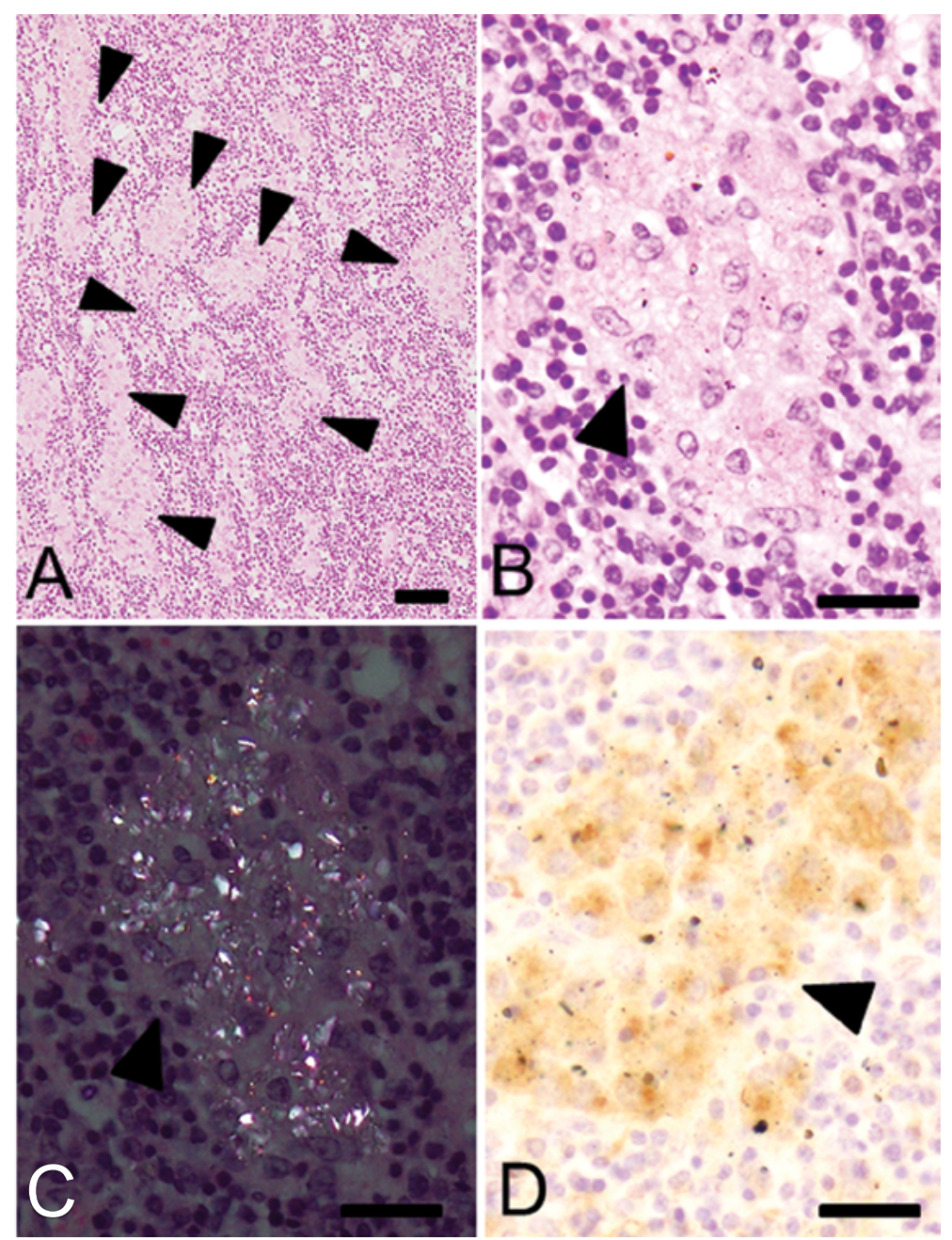

Figure 2. Tracheobronchial lymph nodes in sand storms-exposed sheep. A, B. Granulomatous lesions (black arrowheads, $\mathrm{B}$ is a higher magnification of image A); C. Sand dust particles appeared as birefringent and white crystals under polarized light; D. Macrophages in the granulomatous lesions are positive for lysozyme immunohistochemistry (No. 6). A, B: H \& E staining; C: H \& E stained section in a polarized light; D: lysozyme immunohistochemistry. Scale bars $=50 \mu \mathrm{m}$

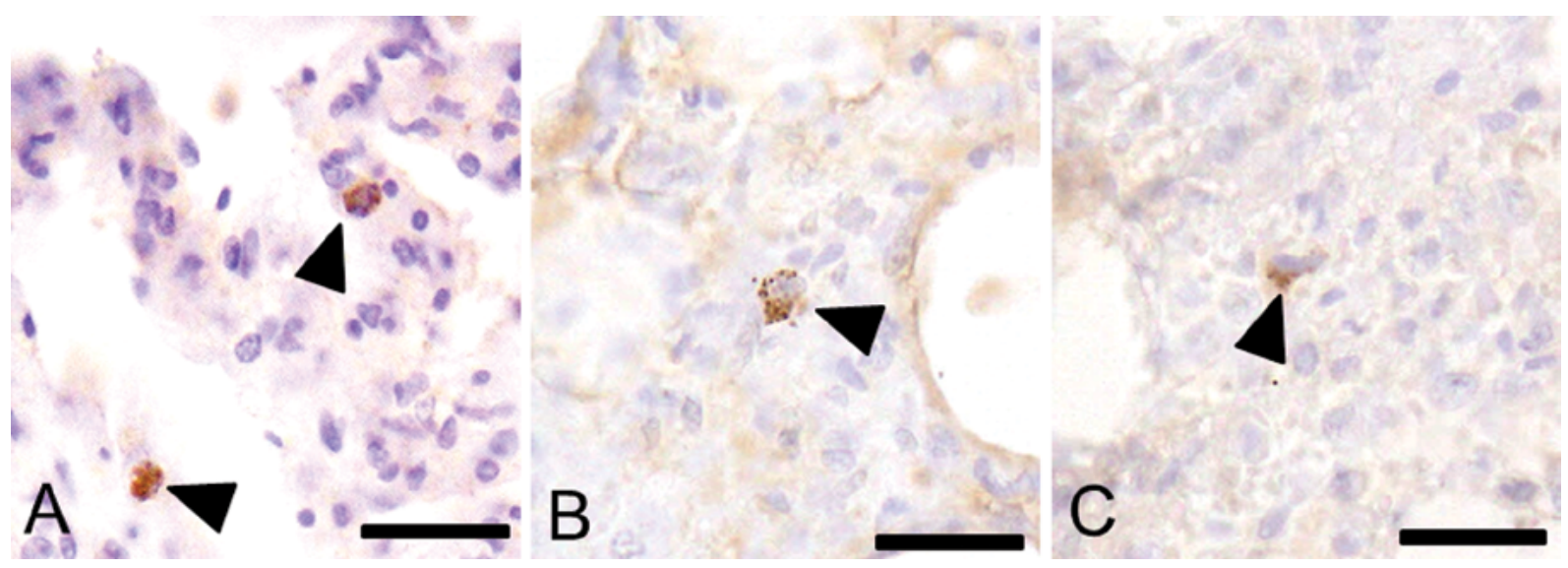

Figure 3. Alveolar macrophages in the lungs of sand-storms-exposed sheep. Increased number of macrophages (black arrowheads) with the presence of lysozyme (A), IL-6 (B) and TNF- $\alpha$ (C) demonstrated by immunohistochemistry. (A, C: sheep No. 6, B: sheep No. 4). Scale bars $=50 \mu \mathrm{m}$ 
Table 2. Content of $\mathrm{Si}$ and $\mathrm{Al}$ in lungs and tracheobronchial lymph nodes in control sheep and animals exposed to sand storms in Mongolia

\begin{tabular}{|l|c|c|c|c|c|c|c|c|}
\hline Sheep & \multicolumn{2}{|c|}{ Control } & \multicolumn{2}{c|}{ Control } & \multicolumn{2}{c|}{$\begin{array}{c}\text { Exposed } \\
\text { No. 4 }\end{array}$} & \multicolumn{2}{c|}{$\begin{array}{c}\text { Exposed } \\
\text { No. 6 . }\end{array}$} \\
\hline Tissue & Lung & LN & Lung & LN & Lung & LN & Lung & LN \\
\hline $\mathrm{Si}[\mu \mathrm{g} / \mathrm{g}]$ & $<20$ & $<20$ & $<20$ & $<20$ & 30 & 30 & 20 & 300 \\
\hline $\mathrm{Al}[\mu \mathrm{g} / \mathrm{g}]$ & 3 & 6 & 2 & 3 & 50 & 60 & 20 & 300 \\
\hline
\end{tabular}

Content of the elements was determined by the way of inductively coupled plasma atomic emission spectroscopy as described in Methods; LN - lymph node

Morphological changes, including emphysema, alveolar thickening, and granulomatous foci, were common in animals exposed to sand storms (Table 1). No signs of viral, bacterial, or parasitic infections were observed in the examined tissues, and there were no inflammatory changes accompanied by infectious agents. Silicon was detected exclusively in the lungs and lymph nodes from exposed animals, which also exhibited higher content of aluminum compared with those from unexposed animals (Table 2).

\section{Discussion}

This study revealed emphysema and diffuse fibrous thickening of alveolar walls in association with IL-6and TNF-positive alveolar macrophages containing sand dust particles in animals exposed to sand storms in Mongolia. The major mineralogical component of ASD is silica $\left(\mathrm{SiO}_{2}\right)$, which is primarily derived from feldspar and quartz (crystalline silica) [19]. Silica is birefringent and white in color under polarized light, as observed in this and previous study [22]. Exposure to quartz (crystalline silica) reportedly induces silicosis, which is characterized by pulmonary fibrosis and granuloma formation [13]. In this study, myofibroblasts, which are positive for $\alpha$-SMA and are involved in fibrosis of damaged lung tissue [27], were observed in the thickened alveoli. A granulomatous response in the lungs and tracheobronchial lymph nodes was also observed in mice exposed to ASD [22]. Involvement of cytokines, including TNF- $\alpha$ and IL-6, in the pulmonary inflammatory changes in patients with silicosis has been reported. TNF- $\alpha$ is associated with the proliferation of fibroblasts and secretion of extracellular matrix components [28]. Since no signs of apparent viral or bacterial infection were detected in the examined tissues, it is likely that sand dust particles inhaled by the animals into the lung tissues were responsible for the observed lung lesions.

Granulomatous inflammation, which involves epithelioid macrophages which contain particles, has been observed in tracheobronchial lymph nodes from rats exposed to crystalline silica $[12,17,18]$ and mice exposed to ASD [22], and translocation of particle-containing macrophages into the tracheobronchial lymph nodes was reported in these studies. It has been suggested that crystalline silica particles transported into the tracheobronchial lymph nodes can react with circulating immunocompetent cells [9]. Similarly to mice with intratracheal inoculation of ASD in which translocation of macrophages containing sand dust particles and retention of these particles in the tracheobronchial lymph nodes was observed [22], we also found such macrophages in the exposed sheep and goats in this study. These findings suggest that exposition of animals, and possibly humans, to sand dust particles may continuously stimulate pulmonary immune system.

In conclusion, the retention of inhaled sand dust particles and morphological changes, including emphysema and fibrous thickening of alveoli, were observed in lungs from sheep and goats exposed to sand storms in Mongolia. In addition, granulomatous lesions comprising macrophages that contained fine sand dust particles were dominant in the tracheobronchial lymph nodes. Naturally occurring sand particles generated by sand storms can be identified in domestic animals at levels similar to those in experimental animals.

\section{Acknowledgments}

The authors received financial support by Special Project (Assessment and Control of Dust Emission in Degraded Drylands of East Asia), MEXT, Japan, for the research, authorship, and/or publication of this article, Grants-in-Aid for Scientific Research (S) (KAKENHI) by Japan Society of the Promotion Science (JSPS) and by a research project grant awarded by the Azabu University.

\section{References}

1. Yeo NK, Hwang YJ, Kim ST et al. Asian sand dust enhances rhinovirus-induced cytokine secretion and viral replication in human nasal epithelial cells. Inhal Toxicol. 2010;22:1038-1045. 
2. Kwon HJ, Cho SH, Chun Y et al. Effects of the Asian dust events on daily mortality in Seoul, Korea. Environ Res. 2002;90:1-5.

3. Hwang SS, Cho SH, Kwon HJ. Effects of the severe Asian dust events on daily mortality during the spring of 2002, in Seoul, Korea. J Prev Med Public Health. 2005;38:197-202.

4. Lee JT, Son JY, Cho YS. A comparison of mortality related to urban air particles between periods with Asian dust days and without Asian dust days in Seoul, Korea, 2000-2004. Environ Res. 2007;105:409-413.

5. Chen YS, Sheen PC, Chen ER et al. Effects of Asian dust storm events on daily mortality in Taipei, Taiwan. Environ Res. 2004;95:151-155.

6. Mori I, Nishikawa M, TanimuraT et al. Change in size distribution and chemical composition of kosa (Asian dust) aerosol during long-range transport. Atmos Environ. 2003;37:4253-4263

7. Griffin DW. Atmospheric movement of microorganisms in clouds of desert dust and implications for human health. Clin Microbiol Rev. 2007;20:459-477.

8. Calvert GM, Rice FL, Boiano JM et al. Occupational silica exposure and risk of various diseases: an analysis using death certificates from 27 states of the United States. Occup Environ Med. 2003;60:122-129.

9. Kumagai N, Nishimura Y, Maeda $\mathrm{M}$ et al. Immunological effects of silica/asbestos. Jpn J Hyg. 2010;65:493-499.

10. Wu P, Miura Y, Hyodoh F et al. Reduced function of $\mathrm{CD} 4+25+$ regulatory $\mathrm{T}$ cell fraction in silicosis patients. Int J Immunopathol Pharmacol. 2006;19:357-368.

11. Green FH, Vallyathan V, Hahn FF. Comparative pathology of environmental lung disease: an overview. Toxicol Pathol. 2007;35:136-147.

12. Huang SH, Hubbs AF, Stanley CF et al. Immunoglobulin responses to experimental silicosis. Toxicol Sci. 2001;59: 108-117.

13. Ishihara $\mathrm{Y}$, Yasuhara $\mathrm{T}$, Ishiyama $\mathrm{S}$ et al. The role of leukocytes during acute phase inflammation in crystalline silica-induced lung injury. Exp Lung Res. 2001;27:589-603.

14. Langley RJ, Kalra R, Mishra NC et al. A biphasic response to silica: I. Immunostimulation is restricted to the early stage of silicosis in lewis rats. Am J Respir Cell Mol Biol. 2004;30:823-829.

15. Langley RJ, Mishra NC, Pena-Philippides JC et al. Granuloma formation induced by low-dose chronic silica inhalation is associated with an anti-apoptotic response in Lewis rats. J Toxicol Environ Health A. 2010;73:669-683.

16. Porter DW, Hubbs AF, Mercer R et al. Progression of lung inflammation and damage in rats after cessation of silica inhalation. Toxicol Sci. 2004;79:370-380.

17. Friedetzky A, Garn H, Kirchner A et al. Histopathological changes in enlarged thoracic lymph nodes during the development of silicosis in rats. Immunobiol. 1998;199:119-132.

18. Porter DW, Millecchia L, Robinson VA et al. Enhanced nitric oxide and reactive oxygen species production and damage after inhalation of silica. Am J Physiol Lung Cell Mol Physiol. 2002;283:L485-L493.

19. Nishikawa M, Hao Q, Morita M. Preparation and evaluation of certified reference materials for Asian mineral dust. Global J Environ Res. 2000;4:103-114.

20. Ichinose $\mathrm{T}$, Nishikawa $\mathrm{M}, \mathrm{Takano} \mathrm{H}$ et al. Pulmonary toxicity induced by intratracheal instillation of Asian yellow dust (kosa) in mice. Environ Toxicol Pharmacol. 2005;20:48-56.

21. Naota M, Mukaiyama T, Shimada A et al. Pathological study of acute pulmonary toxicity induced by intratracheally instilled Asian sand dust (kosa). Toxicol Pathol. 2010;38:1099-1110.

22. Naota M, Shiotsu S, Shimada A et al. Pathological study of chronic pulmonary toxicity induced by intratracheally instilled asian sand dust (kosa). Toxicol Pathol. 2013;41:48-62.

23. Pearson GR, Longstaffe JA, Lucke VM et al. Lymphadenopathy in dogs associated with aluminosilicate. Vet Rec. 1986;118:450-453.

24. Day MJ, Pearson GR, Lucke VM et al. Lesions associated with mineral deposition in the lymph node and lung of the dog. Vet Pathol. 1996;33:29-42.

25. Gao T, Su L, Ma Q et al. Climatic analyses on increasing dust storm frequency in the springs of 2000 and 2001 in Inner Mongolia. Int J Climatol. 2003;23:1743-1755.

26. Matsuyama $\mathrm{S}$, Ishii $\mathrm{K}$, Yamazaki $\mathrm{H}$ et al. Microbeam analysis of yellow sand dust particles. X-Ray Spectrom. 2008;37:151-155.

27. Zhang K, Rekhter MD, Gordon D et al. Myofibroblasts and their role in lung collagen gene expression during pulmonary fibrosis. A combined immunohistochemical and in situ hybridization study. Am J Pathol. 1994;145:114-125.

28. Vanhée D, Gosset P, Boitelle A et al. Cytokines and cytokine network in silicosis and coal workers' pneumoconiosis. Eur Respir J. 1995;8:834-842. 